\title{
AMBULANCE TRACKING SYSTEM BERBASIS WEB PADA RUMAH SAKIT UMUM DAERAH dr. ZAINOEL ABIDIN BANDA ACEH WEB-BASED AMBULANCE TRACKING SYSTEM IN REGIONAL GENERAL HOSPITAL dr. ZAINOEL ABIDIN BANDA ACEH
}

\author{
Muhammad Bayu Wibawa ${ }^{1}$, Mujibullah ${ }^{2}$, Saddam Husein ${ }^{3}$ \\ ${ }^{[1-2]}$ Universitas Ubudiyah Indonesia \\ Jl. Alue Naga Desa Tibang Banda Aceh, 23114 \\ e-mail: mbayuw@uui.ac.id, , ${ }^{2}$ mjee.uui16@gmail.com, ${ }^{3}$ s.husein@ gmail.com
}

\begin{abstract}
Abstrak - Ketersediaan ambulance di Rumah Sakit Umum Daerah dr. Zainoel Abidin (RSUDZA) terkadang sulit diprediksi. Ketika ambulance dibutuhkan sedangkan semua ambulance di rutenya masing- masing, posisi yang pasti tiap ambulance akan sulit ditentukan secara manual. Pada kasus ini, pemanfaatan fungsi GPS pada smartphone yang dihubungkan dengan web melalui PhoneGap atau disebut juga dengan ambulance tracking sistem (ATS) dibangun untuk mengurangi masalah di instalasi kemotoran RSUDZA Banda Aceh. GPS pada smartphone di mobil ambulance akan mengirim titik koordinat latitude/longitude ke satelit dan koordinat posisi tersebut akan dikirim juga ke internet melalui BTS seluler dalam bentuk data tracking. Sementara itu, data tracking yang terdiri dari koordinat posisi mobil ambulance, id_supir, id_ambulans, id_smartphone, waktu keberangkatan dan tujuan mobil ambulance dari internet dikirim ke admin dan disimpan di server. Oleh karena itu, rancangan ini lebih efektif dan efesien karena admin dan supir ambulance dapat berinteraksi melalui sistem tracking.
\end{abstract}

Kata Kunci: Ambulance, Tracking Sistem, PhoneGap, Website, GPS, RSUDZA.

Abstrack - The availability of ambulance(s) in Zainoel Abidin Hospital is sometimes barely to predict. When an ambulance is required while all ambulances are on their routes, the exact position of each ambulance will be difficult to determine manually. In this case, the functionality of GPS on smartphones was linked to the web via PhoneGap or also named as ambulances tracking system which was built to reduce problems at the RSUDZA Banda Aceh sewage installation. The GPS on the smartphone in the ambulance will send the latitude / longitude coordinate point to the satellite then it will be sent to the internet via cellular BTS in the form of tracking data. Meanwhile, the tracking data consisting of ambulance position coordinate, "id_supir", "id_ambulance", "id_smartphone”, departures and destination ambulance from the internet are sent to the admin and stored on the server. Therefore, it is more effective and efficient since the admin and the ambulance driver can interact through the tracking system.

Keywords: ambulance, tracking system, PhoneGap, Website, GPS, RSUDZA.

Keywords: Detention House, Information System, Prisoner Administration, Web

\section{PENDAHULUAN}

Ambulance merupakan salah satu bagian dari rumah sakit yang menangani proses antar jemput pasien dimana masalah utama yang sering dikeluhkan oleh banyak rumah sakit adalah mereka tidak mengetahui dengan pasti dimana posisi mobil ambulance mereka sekarang. Oleh sebab itu, pihak rumah sakit sering kesulitan untuk memantau pekerjaan yang berkaitan dengan pelayanan masyarakat seperti keberadaan mobil ambulance. Keterbatasan pihak rumah sakit dalam memantau mobil ambulance mengakibatkan kekosongan atau ketidakjelasan posisi mobil ambulance, sehingga ketersediaan mobil ambulance yang akan kembali ke rumah sakit tidak dapat diperkirakan.

Untuk mengatasi masalah yang telah dijelaskan, penulis telah merancang aplikasi yang bisa melakukan tracking pada mobil ambulance yang sedang dalam perjalanan mengantar pasien ataupun yang dalam perjalanan kembali ke RSUDZA. Aplikasi yang dibangun ini menggunakan dua aplikasi, yang berjalan dengan basis website yang akan digunakan oleh admin untuk tracking posisi serta aplikasi mobile android yang dijalankan di smartphone untuk memaksimalkan GPS pada mobil ambulance yang mengirimkan titik koordinat latitude dan longitude setiap menit sehingga posisi mobil ambulance tersebut secara terus- menerus dapat dipantau posisinya. Sehingga dengan adanya aplikasi tracking sistem pada mobil ambulance di RSUDZA ini diharapkan akan memudahkan pihak Instalasi Kemotoran dalam mengatur dan mengelola mobil ambulance, agar mobil ambulance selalu tersedia saat dibutuhkan dalam melayani pasien.

\section{STUdi PUSTAKA}

\section{A. Ambulan}

Ambulance merupakan kendaraan roda empat yang 


\section{Universitas Ubudiyah Indonesia}

\section{e-ISSN : 2615-5346}

digunakan untuk membantu pasien terutama dalam mengantar dan menjemput. Pengadaan ambulance pada setiap Klinik, Puskesmas maupun Rumah Sakit yang mendukung Sistem Penanggulangan Gawat Darurat Terpadu Sehari-hari (SPGDT-S) mengacu pada Keputusan Menteri Kesehatan Nomor 882/Menkes/SK/X/2009 tentang Pedoman Penanganan Evakuasi Medik. Di RSUDZA terdapat 26 mobil ambulance dimana 11 merupakan minibus pasien dan 15 lainnya merupakan minibus jenazah. Pengemudi ambulance yang semuanya laki-laki berjumlah 29 orang. Sesuai dengan Surat Keputusan Kebijakan Direktur Badan Layanan Umum Daerah Rumah Sakit Umum Daerah dr. Zainoel Abidin No: 445/65/2014 tentang pelayanan kesehatan Rumah Sakit, terdapat tiga prosedur tata tertib pengemudi ambulance yang meliputi syarat pengemudi ambulance, aturan ambulance gawat darurat di jalan raya, dan menggunakan alat-alat peringatan

\section{B. Google Map}

Google Maps adalah sebuah peta dunia yang dibuat oleh Google (Riyanto: 2010). Layanan Google Maps ini gratis dan dapat kita temukan di http://maps.google.com. Google Maps menawarkan peta yang dapat digeser (panned), diperbesar (zoom in), diperkecil (zoom out), dapat diganti dalam beberapa mode (map, satelite, hybrid, dan lain-lain), fitur pencarian rute (routing), petunjuk arah dari suatu objek peta ke objek yang lain (direction), dan juga pencari tempat (place) bisnis.

\section{PhoneGap}

Menurut Wargo (2012: 3) PhoneGap adalah open source framework untuk membuat crossplatfrom native applications menggunakan teknologi web mulai dari HTML, CSS, dan JavaScript. Tipe dari aplikasi ini disebut sebagai hybrid application. PhoneGap di ciptakan untuk mempermudah mobile development. Dan pendapat Wargo juga (2012: 7) PhoneGap bekerja dengan cara merubah web application package menjadi native application. Aplikasi yang telah dibuat akan ditampilkan dalam bentuk web view yang memungkinkan pengguna untuk melakukan interaksi dengan aplikasi tersebut.

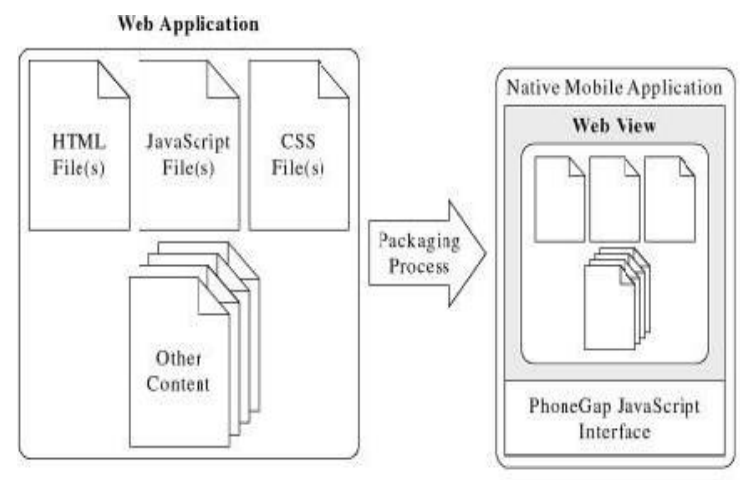

Gambar 1. PhoneGap Application
Penelitian Wargo (2012: 7) pada PhoneGap mendukung platform terkenal antara lain Apple iOS, Google Android, HP/Palm webOS, Microsoft Windows Phone 7, Nokia Symbian, RIM BlackBerry, Samsung Bada. Dikarenakan fungsi setiap platform berbeda-beda, maka PhoneGap menyediakan Application Programming Interface (API) untuk mempermudah pengembang diantaranya adalah Accelerometer, Camera, Capture, Compass, Connection, Contacts, Device, Events, File, Geolocation, Media, Notification, dan Storage. API tersebut dibuat agar pengembang dapat mengakses fungsi native application melalui javascript dengan syntax yang sama di semua platform. Tidak semua platform dapat menggunakan API PhoneGap karena keterbatasan software maupun hardware tiap platform, berikut adalah perbandingan API di masing masing platform.

\section{Web Server}

Untuk dapat mengembangkan aplikasi dengan menggunakan PHP, kita harus memiliki web server dalam komputer kita. Hampir semua web server yang ada pada setiap sistem operasi komputer telah mendukung PHP. Berikut adalah beberapa web server yang paling banyak digunakan dan dapat dipilih untuk kepentingan pengembangan aplikasi web dengan menggunakan PHP (Sidik: 2014) ISS (Internet Information Server), Apache, LightTPD, dan Nginx.

\section{METODE}

\section{A. Perancangan Sistem}

Penelitian ini dilakukan pada Instalasi Kemotoran di RSUZA. Waktu penelitian ini dilakukan selama lima bulan, dimulai dari bulan September 2017 sampai dengan Januari 2018. Selain itu, data yang diperlukan dalam melakukan penelitian ini yaitu data- data yang berhubungan dengan mobil ambulance, supir ambulance serta peraturan- peraturan tentang mobil ambulance yang diproleh di unit Instalasi Kemotoran RSUDZA dan juga smartphone yang terkoneksi sinyal GPS/GSM.

\section{Diagram Tracking Sistem}

Rancangan sistem dalam penelitian ini terdiri dari diagram tracking yang menjelaskan proses tracking mobil ambulance. GPS pada smartphone di mobil ambulance akan mengirim titik koordinat Latitude/ Longitude setiap menit ke satelit dan koordinat posisi tersebut juga di kirim ke internet melalui tower BTS seluler dalam bentuk data tracking.. Diagram dapat dilihat pada Gambar 2. 


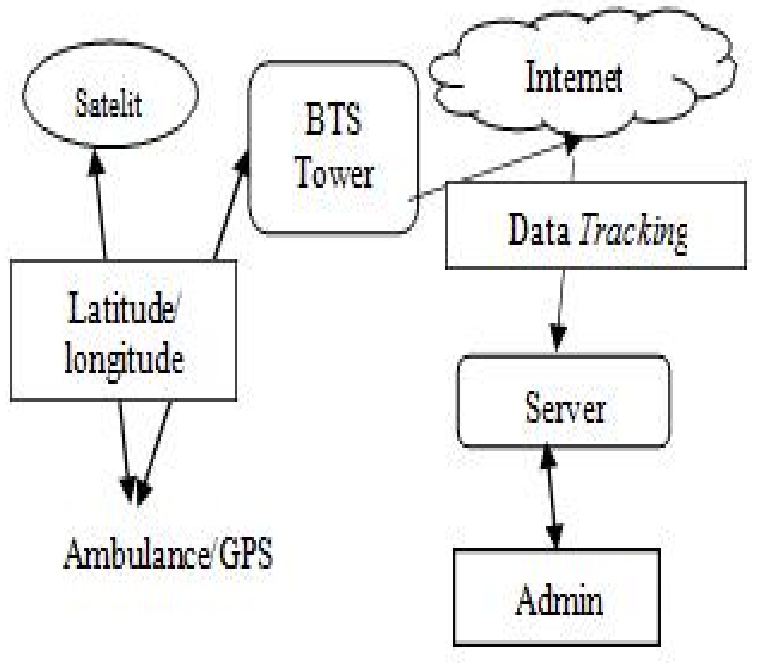

Gambar 2. Diaram Tracking Sistem

2. Database

Tabel - tabel yang disajikan dibawah ini merupakaan hasil dari analisa kebutuhan dari sistem. Tebel - tabel yang digunakan pada database ini antara lain :
a. Tabel admin
b. Tabel mobil
c. Tabel supir
d. Tabel tracking

Tabel 4. Format Tabel Pengujian Sistem

\section{HASIL DAN PEMBAHASAN}

Aplikasi tracking ambulan ini memiliki 2 jenis tampilan, yang pertama tampilan untuk admin berbasiskan web dan yang ke dua tampilan untuk user berbasiskan androi.

\section{Admin}

Gambar 3 menjelaskan setiap mobil ambulance yang berjalan ditandai dengan marker., informasi yang disajikan berisi antara lain: nomor plat dan merek mobil ambulance, nama supir, serta tujuan dari mobil ambulance tersebut. Semua data tracking tersebut harus terlebih dahulu di input oleh admin ke dalam system.

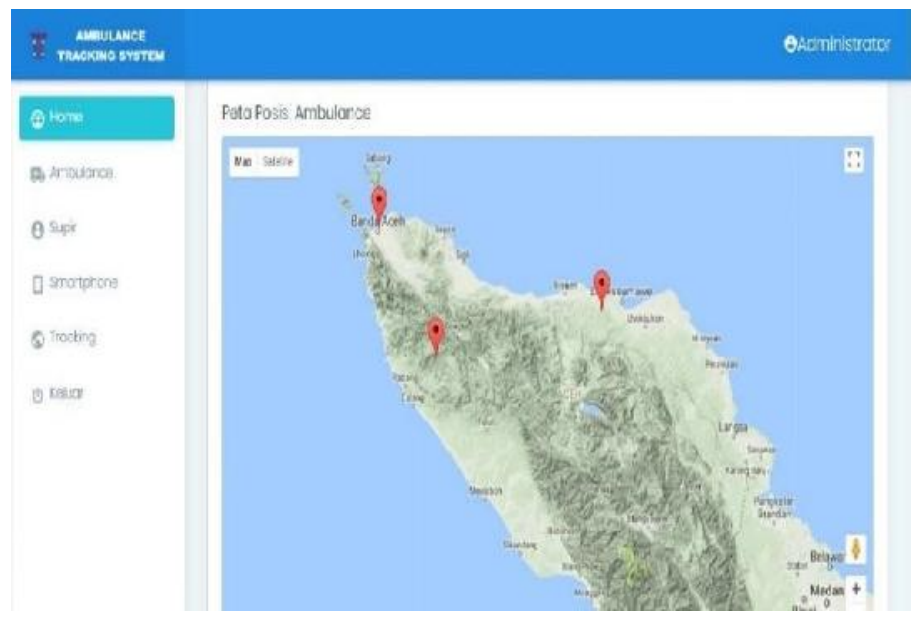

Gambar 3. Peta Posisi Ambulan

2. Tracking Pada Smartphone

Pada aplikasi Smartphone terdapat 3 mnu yang dapat digunakan dalam menjalankan aplikasi tracking mbil ambulan. Menu aplikasi dapat dilahat pada Gambar 4. Tracking Mobil

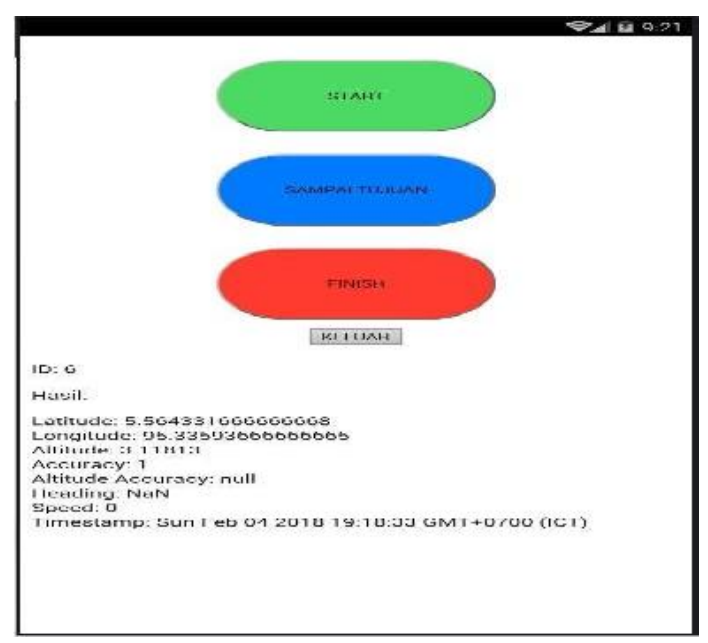

Gambar 4. Tracking Mobil

Tombol-tombol tersebut mempunyai fungsi yang dapat dijelaskan sebagai berikut:

1. Start adalah awal memulai perjalanan mobil ambulance

2. Sampai tujuan adalah tujuan dari mobil ambulance

3. Finish adalah akhir dari perjalanan mobil ambulance

4. Keluar untuk keluar dari aplikasi

5. ID Mobil mobil ambulance yang akan dijalankan

6. Hasil adalah titik koordinat awal mobil ambulance yang keluar dari RSUDZA 


\section{HASIL DAN PEMBAHASAN}

aplikasi Ambulance Tracking System pada RSUDZA ini dapat dengan mudah dan cepat dalam menyajikan mobil ambulance yang sedang melakukan perjalanan. Namun, aplikasi Ambulance Tracking System ini sangat tergantung dari koneksi sinyal smartphone pada mobil ambulance. Sementara itu, kecepatan dalam menampilkan perjalanan mobil ambulance pada map tergantung pada provider dan kestabilan koneksi internet. Di samping itu, aplikasi ATS pada smartphone yang digunakan pada mobil ambulance ini dibangun khusus menggunakan smartphone yang ber platform android.

\section{REFERENSI}

Admi, P. B. (2016) "Sistem Keamanan Kendaraan Bermotor Menggunakan SMS Dengan metode GPS Tracking Berbasis Arduino". Universitas Islam Negeri (UIN) Alauddin Makasar.

Alvianto, R., dan Heru, S. (2015). Aplikasi Sistem Pelacakan Kinerja Pengiriman Pada Truk Pengangkut Barang Berbasis Android. Universitas Muhammadiyah Surakarta.

Dewinta, F., Yoesoef, A., \& Nurasiah. (2017). Perkembangan Rumah Sakit Umum Daerah dr. Zainoel Abidin Tahun 1979-2016. Jurnal Ilmiah Mahasiswa Pendidikan Sejarah FKIP Universitas Syiah Kuala, 2 (2):

Inc, Google, Google. (2012). Overview Google Apps. [Online] Tersedia di: https://developers.google.com/googl e-apps/. [diakses 03 Desember 2016]

Irawati, D. (2016). Sistem Informasi Tracking Jalur Rute Lokasi Chemical Store di Kota Medan Menggunakan Metode

Equirectan gular Approximation. Universitas Potensi Utama Medan.

Kadir, A. (2008). Dasar Pemograman Web Dinamis Menggunakan PHP. Yokyakarta: Penerbit Andi.

Kushwaha, A. \& Kushwaha, V. (2011). Location Based Services using Android Mobile. International Journal of Advances in Engineering \& Technology.

Murad, Dina, F., dan Nia, K. (2013).

Database Melalui Metode DMQ Base Level. Jurnal CCIT. 4 (3).
Nugroho, B. (2013). Dasar Pemograman Web PHP - MySQL dengan Dreamweaver. Yogyakarta: Gava Media.

Riyanto, Membuat Aplikasi Mobile GIS, Yogyakarta: Andi, 2010 .

Safaat, N. (2012). Android: Pemrograman Aplikasi Mobile Smartphone dan Tablet PC Berbasis Android. Bandung: Informatika.

Setiabudi, D. H., Tjahyana, L. J., \& Winsen. (2013). Mobile Learning Application Based on Hybrid Mobile Application Technology Running on Android 86 Smartphone and Blackberry. Doctoral dissertation, Petra Christian University. Retrieved November 9, 2014, 